\title{
Sağlık Araştırmalarında Matematik Model Kullanımı
}

\author{
Mathematical Models in Healthcare \\ ${ }^{1}$ Emine Yaylalı \\ ${ }^{1}$ İstanbul Teknik Üniversitesi, İşletme Fakültesi, Endüstri Mühendisliği Bölümü, İstanbul, Türkiye
}

Emine Yaylalı: http://orcid.org/0000-0002-6707-9521

\begin{abstract}
ÖZ
Sağlık araştırmalarında matematik modellerin uygulanması yeni olmamakla beraber son yıllarda oldukça yaygınlaşmıştır. $\mathrm{Bu}$ artışın nedeni olarak veriyle hesaplama gücündeki artış kadar sağlık maliyetlerinin artması, kaynakların azalması bununla beraber artan yaşam süresi nedeniyle rastlanan kompleks sağlık sorunları da gösterilebilir. Bu çalışma, matematik modellerin sağlık alanındaki uygulamalarını incelemeyi amaçlamakta olup özellikle klinik uygulamaları ve hastalık modellerine önem vermiştir. Bulaşıcı hastalıklar ve kronik hastalıkların modellenmesi bunlara bağlı olarak tedavi ve korunma yöntemlerinin arasından en etkin ve maliyet etkili olanların belirlenmesi önemli bir alandır. Kızamık, grip, kanser ve HIV gibi birçok hastalık ve halk sağlığı sorunu matematik modeller yardımıyla incelenip var olan kaynakların etkin kullanımını sağlayacak karar destek çalışmaları mevcuttur. $\mathrm{Bu}$ çalışmada, bu çalışmaların geniş bir özeti kullanılan matematik modelleme yöntemlerinin sınıflandırılmasıyla verilmiştir. Hastalık model yöntemleri olarak Markov modeller, kompartıman modelleri ve ajan temelli benzetim modelleri metot olarak özetlenmiş ve yapılan önemli çalışmalardan bazıları ve Türkiye'de yapılan uygulamalar incelenmiştir.

Anahtar Kelimeler: Ajan temelli simülasyon, hastalık modelleri, kompartıman modelleri, markov modeller, matematik modelleme
\end{abstract}

\begin{abstract}
In the recent years, healthcare applications of mathematical models have been increasingly developed although the field of healthcare models is not a new area. Current trends could be explained with growing rate of data and computing skills, rising healthcare costs, decreasing resources as well as more complex health problems due to extended life expectancy. In this paper, we survey the mathematical models applied to healthcare problems with a focus on disease applications. Infectious and chronic disease modelling which has been studied for several diseases such as measles, influenza is an important research area. Furthermore, effectiveness and cost-effectiveness of prevention, screening and treatment interventions could be assessed with the help of these models. In this study, we present the definition of mathematical modeling, advantages and disadvantages of modelling and introduce an extensive summary of published literature. We mainly focus on three modeling methodology: Markov models, compartmental models and agent -based simulation.
\end{abstract}

Keywords: Agent-based simulation, compartmental models, disease modeling, markov models, mathematical modeling

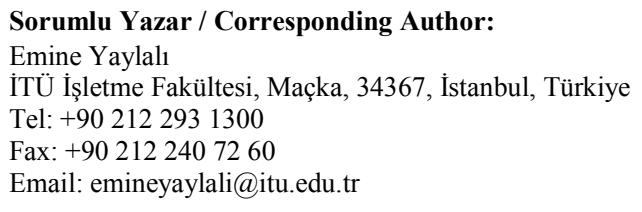

Atıf/ Cited: Yaylalı E. Sağlık araştırmalarında matematik model kullanımı. Online Türk Sağllk Bilimleri Dergisi 2020;5(3):528-540. doi: 10.26453/otjhs.773674

\section{GíRiș}

Sağlık sektörü Türkiye'nin ve dünyanın en büyük sektörlerinden biridir. Artan teknolojiler ve gelişen tıp daha uzun yaşam şansına sebep olurken daha kompleks sorunlara ve maliyetlere yol açabilir. Sağlık harcamaları ABD'de 2007'de gayri safi yurtiçi hasılanın (GSYİH) \%16'sı, Kanada için GSYİH içinde ilk üç sektör arasındadır. ${ }^{1}$ Türkiye'de ise sağlık harcamaları 2009'dan 2015'e kadar yılda \% 10 artış göstererek 58 milyar TL'den 105 milyar TL'ye ulaşmıştır, bu da GSYİH'nın yaklaşık \%
Yayın Bilgisi / Article Info:

Gönderi Tarihi/ Received: 24/07/2020

Kabul Tarihi/ Accepted: 07/09/2020

Online Yayın Tarihi/ Published: 30/09/2020 
lık alanında uygulamalarında çeşitlilik ve sayı açısından önemli bir artış görülmüştür. $\mathrm{Bu}$ örneklerin özetleri Fries, ${ }^{3}$ Pierskalla ve Brailer, ${ }^{4}$ Brandeau ve arkadaşlar1, ${ }^{5}$ Rais ve Vianaa ${ }^{6}$ ve İngiltere'deki uygulamalar için Fakhimi ve Probert" ${ }^{7}$ de bulunabilir. Sağlık alanında matematik model uygulamaları ilk örnekleri hastanelerde operasyonel ve stratejik planlama yapılması üzerine yoğunlaşmış olsa da son yıllarda bir çok farklı sağlık problemi için matematik modelleme uygulamaları yapılmıştır. Sağlıkta matematik model uygulamaları için yapılması gerekenleri özetleyen bir makale serisi de ISPORSMDM modelleme komisyonunun hazırladığı makale serisidir. ${ }^{8-13} \mathrm{Bu}$ makale serisinde çeşitli matematik modelleme yöntemleri ile sağlık çalışmalarında bu uygulamaların doğru yapılması için tavsiyeler ve en iyi uygulama örnekleri sağlanmıştır.

Sağlık araştırmalarında matematik model kullanımı oldukça geniş bir literatürü kapsamakta olup, sağlık sistemlerinin optimal kurgulanması ve organizasyo$\mathrm{nu}$; ameliyathane ve randevu çizelgelemesi; sağlık kurumlarında kapasite, personel ve kaynak yönetimi; sağlık tedarik zincirleri ve kritik stokların (kan, aşı gibi) yönetimi; hastalık modellemesi; tedavi ve koruma yöntemlerinin etkin bir şekilde seçilmesi; daha bir çok konuyu kapsamaktadır. Bu çalışmaları üç ana kategoriye ayırmak istersek: sağlık operasyon yönetimi, bulaşıcı ve bulaşıcı olmayan hastalık modelleri dahil olmak üzere klinik uygulamalar, halk sağlığı politikalarını değerlendiren ekonomik analizler olmak üzere 3'e ayrılabilir. Bütün bu grupları aynı anda incelemek mümkün olmayacağı için bu makalede özellikle hastalık matematik modelleri ve klinik uygulamalar üzerinde yoğunlaşılmıştır. Aşağıda bu alandaki yapılan çalışmalar önce model tiplerine göre ayırılıp alanındaki önemli çalışmalar listelenip incelenmiştir.

Matematik Modelleme Nedir? Matematik modelleme, gerçek bir sistem veya sürecin basitleştirilmiş bir temsilidir. Bunu, sistemi matematik formülleri ile ifade ederek gerçekleştirebiliriz. Matematik modeller gerçek sistemi birebir temsil edemese de modelin uygulandığı sistemi anlamamızı sağlar. Ayrıca, matematik modeller gerçek sistem hakkında deneyler yapmamızı ve sistem ile karar verirken doğru adımları seçmemizi sağlar. George Box'ın ünlü deyişinde bahsettiği gibi bütün modeller yanlıştır ancak çoğu yararlıdırlar.

Matematik modeller doğru uygulanırsa oldukça faydalıdır. Önemli faydalarından biri, gerçek sistem üzerinde yapılması imkansız olan, uzun sürecek olan veya pahalı olabilecek olan alternatiflerin denenmesini sağlamaktır. Mesela, bir salgın durumunda acil durum klinikleri için en uygun yerlerin belirlenmesi problemini gerçek hayatta denenmesi zor iken, matematik modeller yardımıyla bu sorunun cevabı bulunabilir. Bu açıdan matematik modeller, daha ucuz, daha az zaman gerektiren ve alternatif senaryoların daha kolay denenebildiği bir yöntemdir. Aynı zamanda gerçek sistemde karşılaştırılması zor olan alternatifleri aynı kantatif metotlar kullanarak incelenmesini sağlayabilirler. Mesela, HIV için uygulanan biyolojik korunma metotları ile davranışsal korunma metotları modeller yardımıyla incelenebilmektedir. Sağlık alanındaki modeller aynı zamanda yaşam yılı, yaşam kalitesi gibi sağlık çıktılarının maliyetlerle beraber incelenip çeşitli sağlık tedavilerinin ve programlarının karşılaştırılmasını sağlarlar. Modellerin diğer yararlı kullanım alanlarından biri de duyarlılık ve senaryo analizleri yapmanın oldukça kolay olmasındır. Bu yönüyle sadece var olan realiteyi değil de olası diğer senaryoların da sonuçlar1 değerlendirilebilir.

Matematik modellerin yararları çok olmasına rağmen kullanımı sırasında limitlerinin olduğu da unutulmamalıdır. Modeller gerçek sistemin basitleştirilmiş versiyonları olduğundan birebir sonuç ve detay da olmaları beklenmemelidirler. Modellerin doğruluğu kullanılan model metodolojisinin uygun olmasından kullanılan verinin doğruluğuna ve doğru şekilde işlenmesine kadar bir çok aşamayı içerir. Bu açıdan model uygulamaları sırasında veri eksikliği önemli bir sorundur. $\mathrm{Bu}$ durumda uzman görüşüne başvurulabilir. Modellerin doğru kurulması kadar doğru uygulanması da önemlidir. Matematik modeller, sağlık yetkilileri, doktorlar ve araştırmacılar arasında görüş oluşturmak ve doğru politikaları belirlemek için kullanılmalıdır.

\section{METOTLAR VE UYGULAMALAR}

Hastalık modelleri için en sık kullanılan matematik modelleme metotları Markov modelleri, dinamik kompartıman modelleri ve özellikle ajan temelli olmak üzere simülasyon modelleridir. Bu modellerin yardımıyla elde edilen hastalık ile ilgili sonuçlar maliyet etkililik analizi ile incelenebilir. Bu sayede en etkin ve maliyet etkili programlar ve yöntemler seçilebilir. Bu bölümde bu metotları kısaca tanımladıktan ve hastalık modellerinde nasıl kullanıldıkları detaylandırıldıktan sonra metotlarının literatürdeki çeşitli hastalık modeli uygulamalarını özetlemekteyiz. Seçilen çalışmalar yapılan çalışmaların tamamını kapsamamakla birlikte önemli ve farklı örnekle- 
rinde kısa bir seçki sunmaktadır. Özellikle farklı hastalıklar uygulamalarını ve son senelerde yapılan çalışmalara ağırlık verirken alandaki temel ve referans çalışmaları da özetlenen çalışmalara ekledik.

\section{Markov Modeller}

Kohort modeli olarak da bilinen Markov modeller kronik ve bulaşıcı hastalıkların modellenmesi için kullanılabilir. Bunun için bir grup hasta (kohort) ve hastalığın ilerlemesi detaylandırılır. Markov modelleri durum geçiş modellerinin bir örneğidir. Bu modellerde hastalık süreçleri birer durum olarak tanımlanır ve durumlar arasındaki geçiş olasılıkları hastalığın ilerlemesini veya iyileşmesini tasvir edebilir. Örnek verirsek, göğüs kanseri için yapılmış bir Markov modelinde durum seti sağlıklı olmak, göğüs kanseri aşamaları, iyileşme ve ölüm olarak kullanılabilir. Veri durumuna göre çeşitli durumlar birleştirilebilir veya daha detaylandırılabilir. Markov model en basit şekilde durum setini ve bu durum setindeki geçiş olasılıklarını ve sürelerini tanımlayarak oluşturulabilir. Duruma göre bu modellere maliyetler, yaşam yılı ve kaliteye göre ayarlanmış yılı (quality adjusted life years - QALY) gibi sağlık çıktıları ve bu sağlık çıktılarını iyileştirebilecek koruma ve tedavi seçenekleri eklenebilir.

Markov modeller, ayrık zamanlı veya sürekli zamanlı tanımlanabilir. Monte Carlo simülasyonu denilen yöntem kullanarak modelin rastlantısal değerleri birden çok defa çözümlenebilir. Markov modeller anlaması kolay, etkili ve belirli çözüm yöntemleri olan yöntemlerden biridir. Durum seti çok büyük olmadığı sürece hesaplama açısından çok zor olmayan yöntemlerden biri olmakla beraber başka avantajı birçok bilgisayar programında Markov modelleri oluşturmak ve çözmek için gerekli paketler bulunmaktadır. Bu metot, uygulanmak istenilen hastalığın gerçeklerine uygun şekilde yeterli sayıda sağlık/ hastalık durumuyla özetlenebilir ise tavsiye edilir. Seçilen sağlık/hastalık durumları uygulanan hastalığın biyolojik durumuna ve hastalık süreçlerinin arasındaki geçişlere uygun olmalıdır. Modele hastalık taraması, tanı alma, korunma yöntemleri ve tedavi yöntemleri etkililiklerinin ölçülmesi için eklenebilir. ${ }^{13}$ Kohort tipi Markov model durum ve olasılık diyagramının bir örneği Șekil 1'dedir.

Markov modellerin önemli bir şartı Markov özelliğine sahip olma zorunluluğudur. Markov özelliği, durumlar arasındaki geçiş olasılıklarının yalnızca o andaki bulunan duruma bağlı olmasıdır, başka bir şekilde özetlemek gerekirse gelecekteki olası hastalık durumu ne geçmişteki süreçlere ne de bulunulan duruma gelene kadar geçen süreye bağlı değildir. $\mathrm{Bu}$ özellik hastalık ilerleme süreçleri düşünüldüğünde oldukça kısıtlayııı olabilir.

Markov modeller, sadece kohort seviyesinde değil birey seviyesinde de incelenebilir. Birey seviyesi modellere mikrosimülasyon veya birinci derece Monte Carlo simülasyonu da denir. Diğer yaygın kullanılan hastalık Markov modeli metotu Markov Karar Süreci (Markov Decision Process - MDP) denilen yöntemdir. Hastalık doğal ilerlemesi için naif Markov modelleri tavsiye edilirken hastalık süreçlerini etkileyecek tarama ve tedavi yöntemleri ekleniyorsa MDP modeli daha uygun olmaktadır. Markov Karar Süreci'nde hastalı modeline karar verici(ler) eklenerek hastalık sürecini tedavi çeşidi gibi kararlardan birini seçerek etkilediği varsayılır ve bu durumda en iyi sağlık çıktılarını sağlayacak veya en az maliyet sağlayacak karar politikası bulunmaya çalışılır. Markov modellerinin diğer bir yaygın hastalık modeli kullanımı ise Markov modelini karar ağaçları ile birleştirmektir. Bunun literatürdeki örneklerinden birkaç örnek aşağıdaki bölümde verilmiş olup Șekil 2'de genel bir örneğinin diyagramı görülebilir.

Literatürde $\mathrm{HIV},{ }^{14}$ suçiçeği ${ }^{15}{ }^{15} \mathrm{PV}^{16}$ ve Hepatit $\mathrm{C}^{17}$ gibi hastalıklar için Markov modelleri oluşturulmuştur. H1N1 için oluşturulan kısmi gözlenebilir Markov karar süreci modeli de bu grup hastalık modellerine bir örnektir. ${ }^{18} \mathrm{HIV}$ için yapılan diğer önemli bir çalışmada Sanders ve arkadaşları oluşturdukları Markov modeline maliyetleri ve yaşam kalitesini ekleyerek modelin sonuçlarını HIV tarama yapılmaS1 ve sıklığının maliyet etkililiğini araştırmışlardır. ${ }^{19}$ Karar ağacı ve Markov modelin birleştirildiği diğer bir çalışma 10,000 kişilik bir kohort üzerinden Lyme hastalığı için aşılama yapmanın maliyet etkililiğini incelemiştir. $^{20}$ Son zamanlarda yapılan benzer bir çalışmada Markov modeli ve karar ağacı Chagas hastalığının için test yapılmasının maliyet etkililiğinin hesaplanmasında kullanılmıştır. ${ }^{21}$ Simpson ve arkadaşlarının yaptığı çalışmada ise Markov modeli kesik zamanlı benzetim modeliyle karşılaştırılmış ve iki modelin de verdiği sonuçlar benzer bulunmasına rağmen simülasyon modeli daha detaylı sonuç verdiği için daha tercih edilebilir bulunmuştur. ${ }^{14}$ Bulaşıcı hastalıklar için kullanılmak üzere oluşturulmuş genel bir Markov modelinin yapısı Yaesoubi ve Cohen'in çalışmasında bulunabilir. ${ }^{22}$

Literatürde kronik hastalık Markov modelleri daha yaygın olmakla beraber bir çok hastalık için kohort bazlı, bireysel, Monte Carlo, Markov karar süreci ve karar ağacı ile birleştirilmiş Markov modelleri bulunmakta ve bu modeller genellikle maliyet etkililik 
analizi ile birleştirilmektedir. Bu çalışmalardan bir kaç örnek vermek gerekirse, Maillart ve arkadaşları meme kanserinin doğal süreçlerini kısmi gözlenebilir Markov karar süreci olarak temsil edip etkin mamografi taraması politikaları oluşturmak için modeli kullanmışlardır. Burada yazarlar tarama için çeşitli başlangıç yaşları ve tarama sıklıkları arasından mamografinin sensitivite ve spesifitesi göz önüne alınarak Amerikan Kanser Derneği'nin k1lavuzunda yer alan tarama politikaları da dahil olmak üzere ölüm riski ve mamografi sayısını en azami tutan politikaları belirlemişlerdir. ${ }^{23}$ Benzer bir çalışmada, Zhang ve arkadaşları, PSA testi sonuçları üzerinden biyopsi kararlarının yaş bazında QALY değerlerinin en iyilendirilmesi hedefi üzerinden belirlemişlerdir. ${ }^{24}$ Tip 2 diyabet için Mayo Clinic verileri kullanılarak oluşturulan bir Markov Karar Modeli ve versiyonlarında, statin kullanımının optimal başlangıç zamanı $1^{25,26}$ ve hastaların adherans durumları gözüne alındığında kardiyovasküler sorunların engellenmesini sağlayan tedavi kararlarını ${ }^{27}$ belirlemişlerdir. Başka bir çalışmada NASH hastalığı için Markov modeli kullanılarak bariatrik cerrahi yöntemlerin QALY bazında maliyet etkili olduğu hesaplanmıştır. ${ }^{28}$ Markov karar sürecinin kronik hastalıklarında kullanımı ve örnekleri için Steimle ve Denton, ${ }^{29}$ Markov modellerin ekonomik analizle birleştirilmesi için Briggs ve Sculpher, ${ }^{30}$ kronik ve bulaşıcı hastalık Markov modellerinde zamana bağlı durum geçiş olasılıklarının önemini çeşitli hastalık modellerini karşılaştırarak gösteren ve özetleyen Faissol ve arkadaşlarl $^{31}$ ve kronik hastalık yönetiminin ekonomik etkilerini Markov modelleri ile ölçen çalışmaların sistematik analizi içinse Kirsch ${ }^{32}$ in çalışmaları incelenebilir.

Dinamik kompartıman modeli: Kompartıman modelleri özellikle bulaşıcı hastalıkların modellenmesinde en yaygın kullanılan ve en uygun olan modelleme yöntemlerinden biridir. SIR modeli olarak da bilinen bu modelin incelenen hastalığın epidemiyolojisine göre çeşitlendirilebilir. SIR modelleri Susceptible (hastalığa duyarlı), Infectious (bulaşıcı) ve Recovered (iyileşmiş) kelimelerinin baş harflerinden oluşur (Șekil 2). İncelenen popülasyon, bu üç ve gerekirse daha fazla kompartımana bölünür.

İlk kompartıman modeli Kermack ve McKendrick tarafından 1927'de oluşturulmuştur. ${ }^{33}$ Kompartıman modelleri kullanılarak çeşitli bulaşıcı hastalıklar incelenmiştir. SIR modeline ilave olarak $M$ (Maternally Derived Immunity - Doğumdan kazanılmış bağışıklık), E (Exposed - Maruz kalmış) gibi kompartımanlar eklenerek MSEIR, MSEIRS, SEIR, SEIRS, SIR, SIRS, SEI, SEIS, SI ve SIS gibi model- ler oluşturulabilir. ${ }^{34}$ Örneğin eğer modellenen hastalık için anneden geçen geçici IgG antikorları sayesinde yeni doğan bebeklerde bağışıklık olabiliyorsa M kompartımanı modele eklenir. Veya hastalık tedavisi olmayan HIV gibi bir hastalıksa iyileşmiş (R) kompartımanı modele eklenmez.

Bu model, matematiksel olarak kompartımanlardaki insanların hareketini diferansiyel denklem sistemi olarak tanımlanmasıyla formüle edilir. Örneğin, hastalık bulaşmamış insanlar S kompartımanını oluşturur ve bu kompartımana gelen ve giden sayısı doğum (giriş), ölüm (çıkış) ve hastalanma (çıkış) sebebiyle olur ve kompartımanlar arası geçişler oran (rate) olarak hesaplanır. Buna göre Șekil 3 'deki SIR modelinin matematiksel tanımı aşağıdaki gibidir.

$$
\begin{aligned}
& \frac{d S}{d t}=v-\beta S \frac{1}{N}-\mu S \\
& \frac{d I}{d t}=\beta S \frac{I}{N}-\gamma I-\mu I \\
& \frac{d R}{d t}=\gamma I-\mu R
\end{aligned}
$$

$\mathrm{Bu}$ formülde N sistemdeki toplam kişi sayısı, v doğum oranı, $\mu$ ölüm oranı, $S$ hastalığ duyarlı kompartımanındaki kişi sayısı, I bulaşıcı kompartımanındaki kişi sayısı, R iyileşmiş kompartımanındaki kişi sayısı, $\gamma$ iyileşme oranı ve $\beta$ etkin temas oranıdır. $\mathrm{N}$ aynı zamanda $S$, I ve R'ın toplamına eşittir $(\mathrm{N}=$ $\mathrm{S}+\mathrm{I}+\mathrm{R})$. $\beta$ yani etkin temas oranı $\mathrm{S}$ ve I kompartımanındaki bireylerin birbirleriyle olan teması ve her temas sırasındaki bulaşıcılık düzeyinin çarpımına eşittir. Bir diğer anlatımla hastalı̆̆ın toplumdaki bulaşma hızı etkin yayılma hızı ve hasta kişi sayısıyla doğru orantılıdır ( $\left.\beta^{*} \mathrm{I}\right)$. v, $\mu, \gamma$ ve $\beta$ parametrelerinin değerleri seçilen hastalığa uygun olarak literatürden veya veriye dayalı seçilmelidir. Verinin olmad1ğ1 durumlarda uzman görüşüne dayanılarak hipotezle belirlenebilir.

Kompartıman modellerinde önemli bir değer temel çoğalma sayısıdır (R0, basic reproduction number). Temel çoğalma sayısı bulaşıcı bir bireyin tamamen duyarlı bir topluma girdiğinde hastalık bulaştırdığı bireylerin sayısıdır. Bu değer bize yeni bir hastalık tamamen duyarlı bir topluma geldiğinde ve koruma önlemleri yoksa ne olacağını gösterir. Mesela temel çoğalma sayısı 1.5 olan bir hastalık popülasyonun yarısından fazlasına bulaşabilir, eğer $R_{0} 5$ ise tüm bireylerin hasta olacağını öngörebiliriz. Genellikle $\mathrm{R}_{0}<1$ olan hastalıklar müdahale edilmeden de azalarak yok olurlar ama $\mathrm{R}_{0}>1$ olan hastalıklar eğer aşı, karantina, tedavi gibi müdahaleler olmazsa yayılma- 
ya devam ederler. $\mathrm{R}_{0}$ kızamık için 16 , suçiçeği için 11, çiçek hastalığı için 5 ve boğmaca için $3.5-5$ olarak hesaplanmıştır. ${ }^{34}$

Temel SIR modelleri için $\mathrm{R}_{0}$ ve diğer sonuçlar analitik olarak hesaplanabilir. Fakat bu modeller genellikle incelenen bulaşıcı hastalıkla ilgili detayları göz önüne almayabilirler. Daha gerçekçi ve hastalıkla ilgili önemli özellikleri barındıran daha gelişmiş kompartıman modelleri üretilebilir. Örneğin akut veya geç düzey hastalık dönemleri, aşılanmış bireyler ek kompartımanlar olarak eklenebilir. Ayrıca popülasyonun heterojenliği tanımlanabilir. $\mathrm{Bu}$ da hastalıkla ilgili farklı davranışlar veya özellikler barındıran alt grupların tanımlanmasıyla yapılabilir. Gelişmiş ve çok sayıda kompartımanı olan modellerin analitik çözümlerine ulaşmak zor olduğu için bu modeller simüle edilerek sonuçlar elde edilmektedir. Neredeyse bütün bulaşıcı hastalıklar için literatürde kompartıman modeli örneği bulunmaktadır. Sitma, ${ }^{35}$ kızamık, ${ }^{36-39}$ kızamıçık, ${ }^{40}$ Ebola, ${ }^{41}$ TB, ${ }^{42}$ gonore, ${ }^{43}$ HIV ${ }^{44}$ SARS, ${ }^{45}$ MERS, $^{46}$ influenza ${ }^{47-50}$ ve boğma$\mathrm{ca}^{51}$ bu örneklerden bazılarıdır. Bu modellerle ilgili Hethcote ${ }^{34}$ un incelemesi ve Rohani ve Peyman, ${ }^{52}$ in kitabında daha detaylı açıklamalar ve örnekler bulunabilir. Bu örnekler arasında, pandemik influenza özellikle H1N1 için üretilen modellerle Meksika'da başlayan salgının verileri incelenmiş, ${ }^{50} \mathrm{H} 1 \mathrm{~N} 1$ aşıs1nın etkinliği ve maliyet-etkililik analizi yapılmış, ${ }^{49}$ çeşitli ülkelerde uygulanan seyahat yasakları ve kısıtlamalarının etkinliği ve değeri incelenmiştir. ${ }^{48}$

HIV için üretilen kompartıman modellerinde HIV tarama ve tedavi programlarının maliyet etkililik analizi yapılmış, ${ }^{53}$ aşı stratejilerinin olası toplumsal sonuçları ve masrafları hesaplanmıştır. ${ }^{54}$ Diğer bir çalışmada temas öncesi proflaksi (pre-exposure prophlyaxis) uygulanması ve tedavi kapsamının artırılmasının ABD'deki HIV/AIDS salgının ne yönde etkileyeceği araştırılmıştır. ${ }^{44}$

Son olarak COVID-19 için üretilen modellerle, SEIR modelleri kullanılarak salgının yayılımı, önlenmesi ve kapasite planlaması ile ilgili çeşitli çalışmalar yapılmıştır. Öncelikle, bir modelleme çalışması salgının Çin'deki yayılımı sırasında $\mathrm{R}_{0}$ sayısını 2.68 hesaplayarak global bir yayılımı olabileceği uyarısında bulunmuştur. ${ }^{55}$ Diğer bir çalışmada, Maier ve Brockmann $^{56}$ etkili karantina ve izolasyon kullanılmasının salgının yayılımına önemli bir etkisi olduğunu göstermiştir. Benzer bir çalışma, Çin'deki sosyal mesafe uygulamalarının salgının yayılımının azalmasında etkisini ölçüp, bu uygulamaların azaltılması sonrası ikinci bir dalga olasılığını incelemiştir. ${ }^{57}$ Buna benzer bir çok modelleme çalışması Tür- kiye dahil çeşitli ülkeler için yapılmış olup MedRxiv ve BioRxiv gibi sitelerde yayınlanmıştır.

Ajan Temelli simülasyon modelleri: Ajan temelli simülasyon (ATS) birey bazlı yapılan simülasyon modelleri olmakla beraber hastalık modellemesinde de yaygın olarak kullanılmaktadır. Özellikle bulaşıcı hastalık modelleri daha yaygın olmakla beraber kanser, diyabet gibi kronik hastalıklar için de ATS uygulamalarına literatürde rastlanmaktadır. ${ }^{58} \mathrm{Bu}$ tip modellerde ajan adı verilen bağımsız bireylerin veya varlıkların özellikleri ve davranışları betimlenerek model oluşturulur, bu sayede mesela uygulanan bir tedaviye verilen farklı tepkiler gibi bireysel farklılıkların modelde incelenmesi sağlanır. Ajanların çevreleriyle ve birbirleriyle olan ilişkileri ve etkileri de modelin önemli kısımlarından biridir. ATS, kompleks sistemlerin incelenmesinde ve bu kompleks sistemlerin altında yatan ilişkilerin anlaşılmasında ve büyük verilerin anlaşılmasında kullanılabilir.

ATS metodu kullanılarak oluşturulan hastalık modellerinde genelde ajanlar bulaşıcı hastalıklar için hastalık bulaşma ve yayma potansiyeli olan bireyler ve kronik hastalıklar için hastalık süreçlerini incelemeyi sağlayacak şekilde hasta bireyler veya mesela kanser modelleri için kanser veya tümör hücreleri olarak belirlenebilir. Model kohort seviyesinde uygulanacaksa o hasta kohortuna uygun özellikler ajan özellikleri olarak kullanılabilirken toplum seviyesinde yapılacak bulaşıcı hastalık modellerinde özellikle yaş, cinsiyet gibi farklı demografik özellikleri ajan özellikleri olarak tanımlanabilir. $\mathrm{Bu}$ demografik özelliklere bağlı oluşturulan simülasyon toplumuna sentetik popülasyon adı verilir. Sentetik popülasyon, gerçek popülasyonun bir temsili olup bulaşıcı hastalığın yayılımı bu model popülasyonunda hastalık verileri de eklenerek incelebilir. Bu modellerde bireylerin toplumda olası bir salgına karşı göstereceği kendini izole etme veya kişisel hijyeni artırma gibi farklı davranışlar da incelenebilir. ATS'nin başka avantajlarından biri de coğrafik bilgilerin ve sosyal ilişkilerin modele eklenebilmesidir, bu da bulaşıcı hastalık modelleri için yaygın kullanımının sebeplerinden biridir.

Yukarıda özetlediğimiz avantajlarına rağmen ajan temelli simülasyonun kullanımını azaltan dezavantajları da bulunmaktadır. Öncelikle bu model tekniği Markov ve dinamik kompartıman modellerine göre genelde daha çok veriye ihtiyaç duymaktadır. Özellikle sentetik popülasyon oluşturulması sadece veri açısından değil bilgisayar hafızası kullanımı ve model işlem süresi için de diğer modellere göre daha fazladır. Bu tip modellerin diğer bir kısıtı ise birey 
bazlı ve kompleks bir modelleme metodu olduğundan model doğrulaması yapmamın zorluğudur.

ATS uygulamalarına gelirsek bulaşıcı hastalık modelleri yaygındır. Örneğin, PATH modeli HIV için oluşturulmuş ve HIV'nin yaşam boyu maliyeti ve yaşam kalitesinin hesaplanması ${ }^{59}$ ve bulaş riskinin çeşitli risk grupları için hesaplanmasında ${ }^{60}$ kullanılmıştır. Benzer bir şekilde, FRED modeli öncelikle influenza için oluşturulmuş ve H1N1 için aşılamanın devam etmesinin önemini, ${ }^{61}$ çeşitli okul kapatma politikalarının salgına etkisini ${ }^{62}$ incelemiş, sonrasında diğer hastalıklar için de genelleyerek bir platform haline getirilmiştir. ${ }^{63}$ Ebola, ${ }^{64} \mathrm{HPV}^{65}$ ve benzeri birçok bulaşıcı hastalıkla ilgili modeller olmakla beraber diyabet, ${ }^{66}$ kardiyovasküler hastalık$\operatorname{lar}^{67}$ ve obezite ${ }^{68}$ gibi kronik hastalık uygulamaları da bulunmaktadır. Bu uygulamalarda, tarama programlarının sıklığı, diyetin, sigarayı bırakmanın ve zayıflamanın hastalıklara etkisi gibi kişi veya toplum bazında yapılabilecek önlemlerin etkililiği araştırılmıştır. ATS'nin diğer kronik hastalık uygulamaları için Nianoga ve Arah ${ }^{69}$ in sistematik araştırmasina ve $\mathrm{Li}^{58}$ nin derlemesine bakılabilir.

Türkiye için yapılmış modeller: Türkiye'de hastalık modellemeleri yaygın olmamakla beraber literatürde bir kaç örneği bulunmaktadır. Sayan ve arkadaşları $^{70}$ 1986-2016 arası HIV insidansı ve $R_{0}$ hesaplamak için kompartıman modelinden yararlanmışlardır. Daha sonra, benzer bir modelle HIV farkındalık programlarının prevalansın azaltmasında etkili olduğunu bulmuşlardır. ${ }^{71} \mathrm{HCV}$ için yapılan modellerle, gelecek vaka tahminiyle beraber hastalık yükü, ${ }^{72}$ tedavi maliyet-etkililiği ve hastalığın eliminasyonu $^{73}$ incelenmiştir. Koyuncu ve Erol, ${ }^{74}$ pandemik influenza için kaynak ayırma modeli oluşturup Türkiye için uygulamışlardır. Su çiçeği üzerine yapılan bir çalışmada Türkiye'de ikinci doz aşının maliyet-etkili olduğu bulunmuştur. ${ }^{75}$ Karar ağac1 ve Markov modelleri kullanarak pnömoni aşılarının maliyet-etkililiğini iki çalışmada karşılaştırılmıştır. ${ }^{76,77}$ Kronik hastalıklar için bir çalışmada meme kanseri Markov modeli ile karar ağacı birleştirilerek uygulanmış ve erken dönem kanser hastalarında gen testi uygulanmasının maliyet-etkililiği araştırılmıştır. ${ }^{78}$ Benzer bir çalışma, akciğer kanserinde kemoterapi ilaçları arasında maliyet açısından seçim yapmayı sağlamak adına Markov bazlı bir model oluşturmuştur. ${ }^{79}$ Diyabet için oluşturulan bir modelle sigara ve obezite göz önüne alınarak 2025'e kadar prevalans tahmininde bulunulmuştur. ${ }^{80}$ İnme ve kalp hastalıkları için diyet gibi çeşitli önleme politikalarının ne kadar etkili olduğu bir modelle incelenmiştir. ${ }^{81}$

\section{TARTIŞMA VE SONUC}

Matematik modelleme, kronik ve bulaşıcı hastalıkların incelenmesinde etkin bir yöntemdir. Bu sayede, kronik hastalıklar için hastalık seyrinin tahmini, tedavi metotları arasında etkili ve maliyet-etkili çözümlerin seçilmesi, hastalık tarama, tanı ve önleme uygulamalarının hastalı yüküne etkisi gibi araştırmalar yapılabilir. Bulaşıcı hastalıklar için yayılım ve salgın tahminleri, aşı ve karantina gibi koruma politikalarının etkisi ve maliyet-etkililiği, kişisel ve toplumsal önlemlerin incelenmesi gibi önemli sorulara cevaplar bulunabilir. Modelleme; veri, metot ve uygulama iyi olduğu sürece bireysel ve halk sağlığı açısından doğru politikalar oluşturulmasında önemli bir destek oluşturabilir, ancak modelleme uygulamalarında kısitlara ve varsayımlara dikkat edilmeli, güvenilir veriler kullanılmalı, validasyonu yapılmalı, uzman görüşleri dikkate alınmalidir.

Etik Komite Onayı: Bu bir derleme çalışmasıdır. Etik onaya ihtiyaç yoktur.

Çıkar Çatışması: Yazar tarafından herhangi bir çıkar çatışmasının olmadığı bildirilmiştir.

Yazar Katkıları: Fikir -EY; Denetim. Malzemeler - EY Veri Toplanması ve / veya İşleme - EY, Analiz ve / veya Yorum - EY, Yazıyı yazan - EY.

Hakem Değerlendirmesi: Çalışma Editör tarafindan davetli bir derlemedir.

\section{KAYNAKLAR}

1. Denton B, Verter V. Health care O.R. OR MS Today. 2010. http://www.lionhrtpub.com/ab/ wpgen.shtml. Accessed March 9, 2020.

2. Türkiye Odalar ve Borsalar Birliği. Türkiye Sağlık Sektörüne Genel Bakış.; 2017. https:// www.tobb.org.tr/saglik/20171229-tss-genelbakis-tr.pdf. Accessed March 9, 2020.

3. Fries BE. Bibliography of Operations Research in Health-Care Systems. Oper Res. 1976;24 (5):801-814. doi:10.1287/opre.24.5.801

4. Pierskalla WP, Brailer DJ. Applications of operations research in health care delivery. Handbooks Oper Res Manag Sci. 1994;6(C):469-505. doi:10.1016/S0927-0507(05)80094-5

5. Brandeau, Margaret L., Sainfort, Francois, Pierskalla WP. Operations Research and Health Care: A Handbook of Methods and Applications.; 2004. doi:10.1057/jos.2009.8

6. Rais A, Vianaa A. Operations research in health- 
care: A survey. Int Trans Oper Res. 2011;18(1):1 -31. doi:10.1111/j.1475-3995.2010.00767.x

7. Fakhimi M, Probert J. Operations research within UK healthcare: A review. J Enterp Inf Manag. 2013;26(1):21-49. doi:10.1108/17410391311289532

8. Caro JJ, Briggs AH, Siebert U, Kuntz KM. Modeling good research practices-overview: A report of the ISPOR-SMDM modeling good research practices task force-1. Med Decis Mak. 2012;32(5):667-677. doi:10.1177/0272989X12454577

9. Eddy DM, Hollingworth W, Caro JJ, Tsevat J, McDonald KM, Wong JB. Model transparency and validation: A report of the ISPOR-SMDM modeling good research practices task force-7. Med Decis Mak. 2012;32(5):733-743. doi:10.1177/0272989X12454579

10. Briggs AH, Weinstein MC, Fenwick EAL, Karnon J, Sculpher MJ, Paltiel AD. Model parameter estimation and uncertainty analysis: A report of the ISPOR-SMDM modeling good research practices task force working group-6. Med Decis Mak. 2012;32(5):722-732. doi:10.1177/0272989X12458348

11. Roberts M, Russell LB, Paltiel AD, Chambers M, McEwan P, Krahn M. Conceptualizing a model: A report of the ISPOR-SMDM modeling good research practices task force-2. Med Decis Mak. 2012;32(5):678-689. doi:10.1177/0272989X12454941

12. Karnon J, Stahl J, Brennan A, Caro JJ, Mar J, Möller J. Modeling using discrete event simulation: A report of the ISPOR-SMDM modeling good research practices task force-4. Med Decis Mak. 2012;32(5):701-711. doi:10.1177/0272989X12455462

13. Siebert U, Alagoz O, Bayoumi AM, et al. Statetransition modeling: A report of the ISPORSMDM modeling good research practices task force-3. Med Decis Mak. 2012;32(5):690-700. doi:10.1177/0272989X12455463

14. Simpson KN, Strassburger A, Jones WJ, Dietz B, Rajagopalan R. Comparison of Markov model and discrete-event simulation techniques for HIV. Pharmacoeconomics. 2009;27(2):159-165. doi:10.2165/00019053-200927020-00006

15. Meltzer MI, Damon I, Leduc JW, Donald Millar J. Modeling Potential Responses to Smallpox as a Bioterrorist Weapon. Vol 7. http:// www.cdc.gov/ncidod/eid/vol7no6/. Accessed March 9, 2020.
16. Myers ER, McCrory DC, Nanda K, Bastian L, Matchar DB. Mathematical model for the natural history of human papillomavirus infection and cervical carcinogenesis. Am J Epidemiol. 2000;151(12):1158-1171. doi:10.1093/ oxfordjournals.aje.a010166

17. Chhatwal J, Kanwal F, Roberts MS, Dunn MA. Cost-effectiveness and budget impact of hepatitis $\mathrm{C}$ virus treatment with sofosbuvir and ledipasvir in the United States. Ann Intern Med. 2015;162 (6):397-406.

18. Yaylali E, Ivy JS, Taheri J. Systems engineering methods for enhancing the value stream in public health preparedness: The role of Markov models, simulation, and optimization. Public Health Rep. 2014;129. doi:10.1177/00333549141296S419

19. Sanders GD, Bayoumi AM, Sundaram V, et al. Cost-effectiveness of screening for HIV in the era of highly active antiretroviral therapy. N Engl J Med. 2005;352(6):570-585.

20. Shadick NA, Liang MH, Phillips CB, Fossel K, Kuntz KM. The cost-effectiveness of vaccination against Lyme disease. Arch Intern Med. 2001;161(4):554-561. doi:10.1001/ archinte.161.4.554

21. Requena-Méndez A, Bussion S, Aldasoro E, et al. Cost-effectiveness of Chagas disease screening in Latin American migrants at primary health-care centres in Europe: a Markov model analysis. Lancet Glob Heal. 2017;5(4):e439e447. doi:10.1016/S2214-109X(17)30073-6

22. Yaesoubi R, Cohen T. Generalized Markov models of infectious disease spread: A novel framework for developing dynamic health policies. Eur J Oper Res. 2011;215(3):679-687. doi:10.1016/j.ejor.2011.07.016

23. Maillart LM, Ivy JS, Ransom S, Diehl K. Assessing dynamic breast cancer screening policies. Oper Res. 2008;56(6):1411-1427. doi:10.1287/ opre. 1080.0614

24. Zhang J, Denton BT, Balasubramanian H, et al. Optimization of PSA-Based Screening Decisions for Prostate Cancer Detection Preventive Followup Policies for Cardiovascular Diseases View Project Treatment Planning-Modeling View Project Optimization of PSA-Based Screening Decisions for Prostate Cancer D.; 2009. https:// www.researchgate.net/publication/228589623. Accessed March 25, 2020.

25. Denton BT, Kurt M, Shah ND, Bryant SC, Smith SA. Optimizing the start time of statin therapy for patients with diabetes. Med Decis 
Mak.

2009;29(3):351-367. doi:10.1177/0272989X08329462

26. Kurt M, Denton BT, Schaefer AJ, Shah ND, Smith SA. Type 2 diabetes. IIE Trans Healthc Syst Eng. 2011;1(1):49-65. doi:10.1080/19488300.2010.550180

27. Mason JE, England DA, Denton BT, Smith SA, Kurt M, Shah ND. Optimizing statin treatment decisions for diabetes patients in the presence of uncertain future adherence. Med Decis Mak. 2012;32(1):154-166. doi:10.1177/0272989X11404076

28. Klebanoff MJ, Corey KE, Samur S, et al. Costeffectiveness Analysis of Bariatric Surgery for Patients With Nonalcoholic Steatohepatitis Cirrhosis. JAMA Netw open. 2019;2(2):e190047. doi:10.1001/jamanetworkopen.2019.0047

29. Steimle LN, Denton BT. Markov decision processes for screening and treatment of chronic diseases. In: International Series in Operations Research and Management Science. Vol 248. Springer New York LLC; 2017:189-222. doi:10.1007/978-3-319-47766-4_6

30. Briggs A, Sculpher M. An introduction to Markov modelling for economic evaluation. Pharmacoeconomics. 1998;13(4):397-409. doi:10.2165/00019053-199813040-00003

31. Faissol DM, Griffin PM, Swann JL. Bias in Markov models of disease. Math Biosci. 2009;220 (2):143-156. doi:10.1016/j.mbs.2009.05.005

32. Kirsch F. Economic Evaluations of Multicomponent Disease Management Programs with Markov Models: A Systematic Review. Value Heal. 2016;19(8):1039-1054. doi:10.1016/ j.jval.2016.07.004

33. WO Kermack AM. A contribution to the mathematical theory of epidemics. Proc R Soc London Ser A, Contain Pap a Math Phys Character. 1927;115(772):700-721. doi:10.1098/ rspa.1927.0118

34. Hethcote HW. Mathematics of infectious diseases. SIAM Rev. 2000;42(4):599-653. doi:10.1137/S0036144500371907

35. Lindsay SW, Hole DG, Hutchinson RA, Richards SA, Willis SG. Assessing the future threat from vivax malaria in the United Kingdom using two markedly different modelling approaches. Malar J. 2010;9(1):70.

36. McLean AR, Anderson RM. Measles in developing countries. Part II. The predicted impact of mass vaccination. Epidemiol Infect. 1988;100 (3):419-442. doi:10.1017/S0950268800067170
37. Ferrari MJ, Grais RF, Bharti N, et al. The dynamics of measles in sub-Saharan Africa. Nature. 2008;451(7179):679-684. doi:10.1038/ nature 06509

38. Zhou L, Wang Y, Xiao Y, Li MY. Global dynamics of a discrete age-structured SIR epidemic model with applications to measles vaccination strategies. Math Biosci. 2019;308:27-37. doi:10.1016/j.mbs.2018.12.003

39. Thakkar N, Gilani SSA, Hasan Q, McCarthy KA. Decreasing measles burden by optimizing campaign timing. Proc Natl Acad Sci U S A. 2019;166(22):11069-11073. doi:10.1073/ pnas. 1818433116

40. Metcalf CJE, Lessler J, Klepac P, Morice A, Grenfell BT, Bjørnstad ON. Structured models of infectious disease: Inference with discrete data. Theor Popul Biol. 2012;82(4):275-282. doi:10.1016/j.tpb.2011.12.001

41. Pandey A, Atkins KE, Medlock J, et al. Strategies for containing Ebola in West Africa. Science. 2014;346(6212):991-995. doi:10.1126/ science. 1260612

42. Dye C, Williams BG. The population dynamics and control of tuberculosis. Science. 2010;328 (5980):856-861. doi:10.1126/science. 1185449

43. Chan CH, McCabe CJ, Fisman DN. Core groups, antimicrobial resistance and rebound in gonorrhoea in North America. Sex Transm Infect. 2012;88(3):200-204. doi:10.1136/sextrans-2011050049

44. Khurana N, Yaylali E, Farnham PG, et al. Impact of Improved HIV Care and Treatment on PrEP Effectiveness in the United States, 20162020. JAIDS J Acquir Immune Defic Syndr. 2018;78(4):399-405.

45. Lipsitch M, Cohen T, Cooper B, et al. Transmission dynamics and control of severe acute respiratory syndrome. Science. 2003;300(5627):19661970. doi:10.1126/science. 1086616

46. Chowell G, Blumberg S, Simonsen L, Miller MA, Viboud C. Synthesizing data and models for the spread of MERS-CoV, 2013: Key role of index cases and hospital transmission. Epidemics. 2014;9:40-51. doi:10.1016/ j.epidem.2014.09.011

47. Coburn BJ, Wagner BG, Blower S. Modeling influenza epidemics and pandemics: insights into the future of swine flu (H1N1). BMC Med. 2009;7(1):30.

48. Bajardi P, Poletto C, Ramasco JJ, Tizzoni M, Colizza V, Vespignani A. Human Mobility 
Networks, Travel Restrictions, and the Global Spread of 2009 H1N1 Pandemic. Perc M, ed. PLoS One. 2011;6(1):e16591. doi:10.1371/ journal.pone.0016591

49. Khazeni N. Effectiveness and Cost-Effectiveness of Vaccination Against Pandemic Influenza (H1N1) 2009. Ann Intern Med. 2009;151 (12):829. doi:10.7326/0000605-20091215000157

50. Fraser C, Donnelly CA, Cauchemez S, et al. Pandemic potential of a strain of influenza A (H1N1): Early findings. Science. 2009;324 (5934):1557-1561. doi:10.1126/science. 1176062

51. Hethcote HW. An age-structured model for pertussis transmission. Math Biosci. 1997;145(2):89 -136. doi:10.1016/S0025-5564(97)00014-X

52. Keeling MJ, Rohani P. Modeling Infectious Diseases in Humans and Animals. Princeton University Press; 2011. doi:10.1016/s1473-3099(08) 70147-6

53. Long EF, Brandeau ML, Owens DK. The costeffectiveness and population outcomes of expanded HIV screening and antiretroviral treatment in the united states. Ann Intern Med. 2010;153 (12):778-789. doi:10.7326/0003-4819-153-12201012210-00004

54. Long EF, Brandeau ML, Owens DK. Potential population health outcomes and expenditures of HIV vaccination strategies in the United States. Vaccine. 2009;27(39):5402-5410. doi:10.1016/ j.vaccine.2009.06.063

55. Wu JT, Leung K, Leung GM. Nowcasting and forecasting the potential domestic and international spread of the 2019-nCoV outbreak originating in Wuhan, China: a modelling study. Lancet. 2020;395(10225):689-697. doi:10.1016/S01406736(20)30260-9

56. Maier BF, Brockmann D. Effective containment explains subexponential growth in recent confirmed COVID-19 cases in China. Science. 2020;368(6492):742-746. doi:10.1126/ science.abb4557

57. Prem K, Liu Y, Russell TW, et al. The effect of control strategies to reduce social mixing on outcomes of the COVID-19 epidemic in Wuhan, China: a modelling study. Lancet Public Heal. 2020;5(5):e261-e270. doi:10.1016/S2468-2667 (20)30073-6

58. Li Y, Lawley MA, Siscovick DS, Zhang D, Pagán JA. Agent-based modeling of chronic diseases: A narrative review and future research directions. Prev Chronic Dis. 2016;13(5). doi:10.5888/pcd13.150561

59. Farnham PG, Gopalappa C, Sansom SL, et al. Updates of lifetime costs of care and quality-oflife estimates for HIV-infected persons in the United States: late versus early diagnosis and entry into care. JAIDS J Acquir Immune Defic Syndr. 2013;64(2):183-189.

60. Gopalappa C, Farnham PG, Chen YH, Sansom SL. Progression and Transmission of HIV/AIDS (PATH 2.0): A New, Agent-ased Model to Estimate HIV Transmissions in the United States. Med Decis Mak. 2016;37(2):224-233. doi:10.1177/0272989X16668509

61. Lee BY, Brown ST, Cooley P, et al. Vaccination deep into a pandemic wave: Potential mechanisms for a "third wave" and the impact of vaccination. Am J Prev Med. 2010;39(5):e21-e29. doi:10.1016/j.amepre.2010.07.014

62. Lee BY, Brown ST, Cooley P, et al. Simulating school closure strategies to titigate an influenza epidemic. J Public Heal Manag Pract. 2010;16 (3):252-261. doi:10.1097/ PHH.0b013e3181ce594e

63. Grefenstette JJ, Brown ST, Rosenfeld R, et al. FRED (A Framework for Reconstructing Epidemic Dynamics): An open-source software system for modeling infectious diseases and control strategies using census-based populations. BMC Public Health. 2013;13(1):940. doi:10.1186/1471 -2458-13-940

64. Merler S, Ajelli M, Fumanelli L, et al. Spatiotemporal spread of the 2014 outbreak of Ebola virus disease in Liberia and the effectiveness of non-pharmaceutical interventions: A computational modelling analysis. Lancet Infect Dis. 2015;15(2):204-211. doi:10.1016/S1473-3099 (14)71074-6

65. Olsen J, Jepsen MR. Human papillomavirus transmission and cost-effectiveness of introducing quadrivalent HPV vaccination in Denmark. Int J Technol Assess Health Care. 2010;26 (2):183-191. doi:10.1017/S0266462310000085

66. Day TE, Ravi N, Xian H, Brugh A. An AgentBased Modeling Template for a Cohort of Veterans with Diabetic Retinopathy. Chaum E, ed. PLoS One. 2013;8(6):e66812. doi:10.1371/ journal.pone.0066812

67. Li Y, Kong N, Lawley M, Weiss L, Pagán JA. Advancing the use of evidence-based decisionmaking in local health departments with systems science methodologies. Am J Public Health. 2015;105 Suppl 2(S2):S217-22. doi:10.2105/ 


\section{AJPH.2014.302077}

68. Hammond RA, Ornstein JT. A model of social influence on body mass index. Ann N Y Acad Sci. 2014;1331(1):34-42. doi:10.1111/ nyas. 12344

69. Nianogo RA, Arah OA. Agent-based modeling of noncommunicable diseases: A systematic review. Am J Public Health. 2015;105(3):e20-e31. doi:10.2105/AJPH.2014.302426

70. Sayan M, Hınçal E, Şanlıdağ T, Kaymakamzade B, Sa'ad FT, Baba IA. Dynamics of HIV/AIDS in Turkey from 1985 to 2016. Qual Quant. 2018;52(1):711-723. doi:10.1007/s11135-0170648-7

71. Kaymakamzade B, Şanlıdağ T, Hınçal E, Sayan M, Sa'ad FT, Baba IA. Role of awareness in controlling HIV/AIDS: a mathematical model. Qual Quant. 2018;52(1):625-637. doi:10.1007/ s11135-017-0640-2

72. Örmeci N, Malhan S, Balık İ, Ergör G, Razavi $\mathrm{H}$, Robbins S. Scenarios to manage the hepatitis $\mathrm{C}$ disease burden and associated economic impact of treatment in Turkey. Hepatol Int. 2017;11 (6):509-516.

73. Yaylali E, Ozdemir B, Lacin N, Ceyil S. Modelling Hepatitis C Infections Among People Who Inject Drugs in Turkey: Is HCV Elimination Possible? In: Calisir F, Korhan O, eds. Industrial Engineering in the Digital Disruption Era: Selected Papers from the Global Joint Conference on Industrial Engineering and Its Application Areas, GJCIE 2019. Springer, Cham; 2020:360-374. doi:10.1007/978-3-030-42416-9_32

74. Koyuncu M, Erol R. Optimal resource allocation model to mitigate the impact of pandemic influenza: A case study for Turkey. J Med Syst. 2010;34(1):61-70. doi:10.1007/s10916-008-9216 $-\mathrm{y}$

75. Wolfson LJ, Daniels VJ, Pillsbury M, et al. Cost -effectiveness analysis of universal varicella vaccination in Turkey using a dynamic transmission model. PLoS One. 2019;14(8):e0220921. doi:10.1371/journal.pone.0220921

76. Bakir M, Türel Ö, Topachevskyi O. Costeffectiveness of new pneumococcal conjugate vaccines in Turkey: A decision analytical model. BMC Health Serv Res. 2012;12(1). doi:10.1186/1472-6963-12-386

77. Marijam A, Olbrecht J, Ozakay A, Eken V, Meszaros K. Cost-Effectiveness Comparison of Pneumococcal Conjugate Vaccines in Turkish Children. Value Heal Reg Issues. 2019;19:34-44. doi:10.1016/j.vhri.2018.11.007

78. Ozmen V, Cakar B, Gokmen E, et al. Cost effectiveness of Gene Expression Profiling in Patients with Early-Stage Breast Cancer in a MiddleIncome Country, Turkey: Results of a Prospective Multicenter Study. Eur J Breast Heal. 2019;15 (3):183-190. doi:10.5152/ejbh.2019.4761

79. Balçik PY, Şahin B. Cost-effectiveness analysis of pemetrexed and gemcitabine treatment for advanced nonsmall cell lung cancer in turkey. Turkish J Med Sci. 2016;46(1):152-158. doi:10.3906/sag-1408-4

80. Sözmen K, Unal B, Capewell S, Critchley J, O'Flaherty M. Estimating diabetes prevalence in Turkey in 2025 with and without possible interventions to reduce obesity and smoking prevalence, using a modelling approach. Int J Public Health. 2014;60(1):13-21. doi:10.1007/s00038014-0622-2

81. Islek D, Sozmen K, Unal B, et al. Estimating the potential contribution of stroke treatments and preventative policies to reduce the stroke and ischemic heart disease mortality in Turkey up to 2032: a modelling study. BMC Public Health. 2016;16(1):46. doi:10.1186/s12889-015-2655-8

82. Kretzschmar M, Wallinga J. Mathematical Models in Infectious Disease Epidemiology. In: Krämer A, Kretzschmar M, Krickeberg K, eds. Modern Infectious Disease Epidemiology. New York, NY: Springer; 2009:209-221. doi:10.1007/978-0-387-93835-6_12 
Start
after 1 year

after 2 years

after 5 years

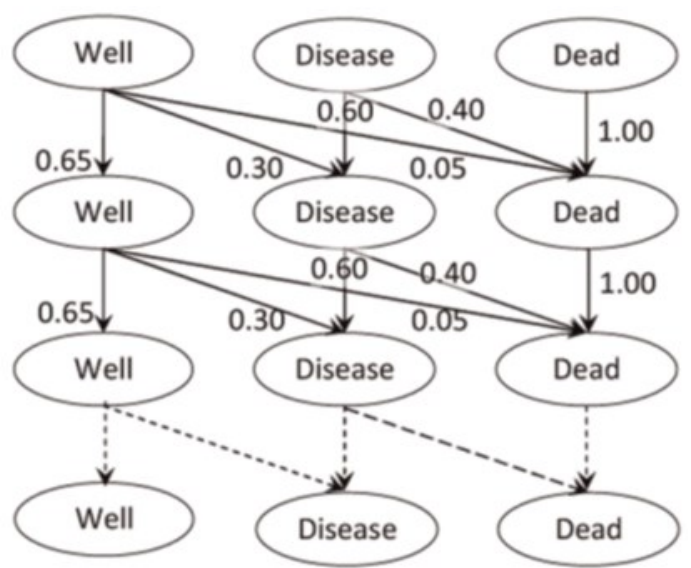

Cohort

$11.6 \%$

$23.0 \%$

$65.4 \%$

Şekil 1. Kohort tipi Markov modeli diagram $1^{13}$ 


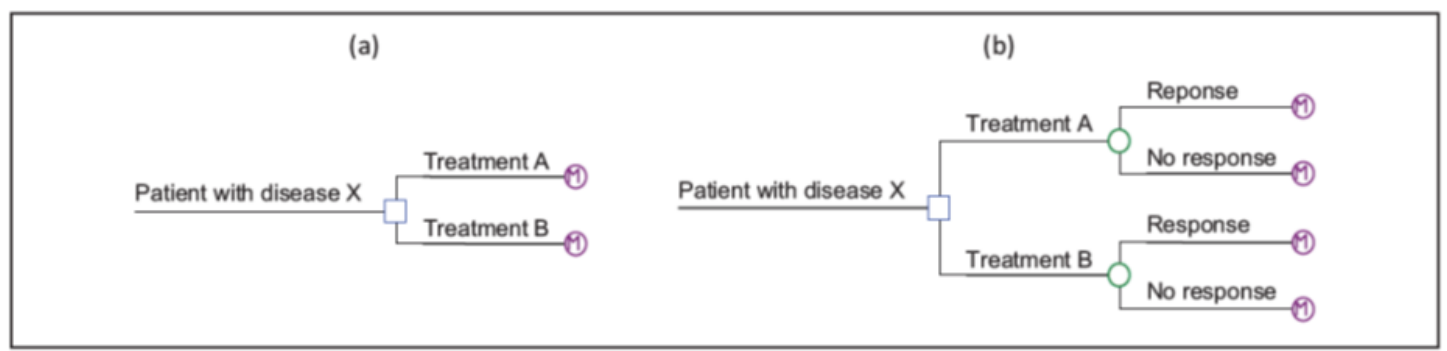

Sekil 2. Karar ağacı ve Markov modelinin birlikte kullanımı genel diyagramı. Bu șekilde M ile işaretlenen kısımlar ayrı Markov modelleridir. (a) modelinde sadece tedaviye bağlı olarak kullanılan Markov modeli değişmekte iken (b) modelinde tedavinin rassal sonucu da modele eklenmiştir ${ }^{13}$. 


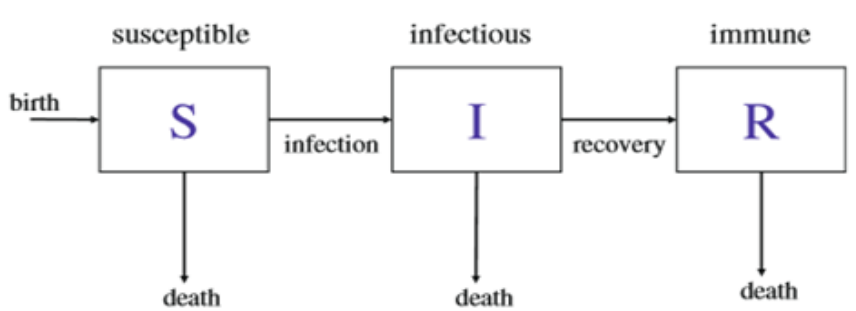

Şekil 3. SIR modeli ${ }^{82}$ 